\title{
Does High Unemployment Rate Cause High Suicide Rate? Evidence from Japan and South Korea
}

\author{
Chiung-Ju Huang ${ }^{*}$ and Yuan-Hong Ho
}

\author{
Department of Public Finance, Feng Chia University, Taiwan
}

\begin{abstract}
This study utilizes an asymmetric Granger causality test suggested by Hatemi-J (2012) to examine the causal relationship running from unemployment rate to suicide rate over the period of 1985 to 2012 in Japan and South Korea. Empirical results show that no Granger causality running from unemployment rate to suicide rate exists in Japan. However, results show that for South Korea, Granger causality exists running from a negative unemployment rate shock to a negative shock in suicide rate. More specifically, a decrease in unemployment rate leads to a decrease in suicide rate. Although the findings of this study do not support that an increase in unemployment rate has led to an increase in suicide rate for Japan and South Korea, a decrease in unemployment rate leads to a decrease in suicide rate in South Korea. Therefore, policy makers in South Korea could decrease unemployment rate to cause a decrease in suicide rate.
\end{abstract}

Keywords: Asymmetric Granger causality test, Unemployment rate, Suicide rate.

\section{INTRODUCTION}

Suicide is a global phenomenon impacting all regions of the world and is a serious global public health problem. According to the World Health Organization (WHO) report "Preventing Suicide: $A$ Global Imperative", each year more than 800,000 people take their own lives - about one person every 40 seconds. ${ }^{1}$ As shown in Table 1, an estimated $75 \%$ of the world's suicides occurred in low and middleincome countries. The suicide rate in the South-East Asia Region accounted for $39 \%$ of global suicides is the highest among all regions.

The center of gravity of the problem of suicide mortality transferred from Western Europe to Eastern Europe, but now seems to have shifted to Asia (Värnik, 2012). However, while Japan and South Korea do not represent underdeveloped economies, they are the top two Asian countries with the highest suicide rates. In 2012, the suicide rates of South Korea and Japan were 29.1 and 19.1 per 100,000 people respectively. The cases of Japan and Korea are very intriguing. Why do some of the world's most developed and wealthy countries have such high suicide rates?

According to the OECD Health Statistics 2015, South Korea's suicide rate is 29.1 in 2012 , about 2.5

*Address of correspondence to this author at the Department of Public Finance, Feng Chia University, Taichung 40724, Taiwan; Tel: +886-424517250 Ext. 4307; Fax: +886-4-35072120; E-mail: cjhuang@fcu.edu.tw

${ }^{1}$ The WHO launched its first global report on suicide "Preventing suicide: a global imperative" in September 2014. The report shows that an estimated 804,000 suicide deaths occurred worldwide in 2012, representing an annual global age-standardized suicide rate of 11.4 per 100,000 people.

E-ISSN: 1929-7092/16 times greater than the OECD average of 11.9. South Korea's suicide rate is No. 1 for the $11^{\text {th }}$ year in a row among OECD countries. One reason for the cause of South Korea's high suicide rate compared to other countries in the developed world is due to a large amount of suicide among the elderly. High suicide rate among elderly South Koreans is due to economic support and poverty, social isolation, and family structure. During recent decades, the rapid economic growth and modernization occurring in South Korea has been associated with powerful socio cultural changes. The old social structure where children looked after their parents has largely disappeared. Disintegrating the traditional family unit and leaving many people feeling isolated and alone as well as combined with a poorly-funded social safety net for the elderly, these result in poor elderly people committing suicide.

Generally speaking, the main reasons for contemplating suicide in South Korea are that children and young adults face the stress of living in a hyper competitive society or pressure over exam results and college entrance, middle-aged South Koreans concern the personal economic problems, and the elderly feel isolation as a result of the breakdown of the traditional family unit.

As to the Japan's suicide rate, it is around $60 \%$ higher than the OECD average in 2012. For the Japan's elderly, the situation is similar in South Korea, the children used to take care of their parents in old age but now not any more. In addition, Japan was once known as the land of lifetime employment. However, opportunities for young people to find a stable full time job have decreased in recent. Nearly $40 \%$ of young people in Japan are unable to find stable jobs while 
Table 1: Regional Distribution of Global Suicides, 2012

\begin{tabular}{|c|c|}
\hline \multicolumn{1}{|c|}{ Region } & \% of global suicide \\
\hline \hline Low and middle-income countries in Africa & 8 \\
\hline Low and middle-income countries in the Americas & 4 \\
\hline Low and middle-income countries in Eastern Mediterranean & 4 \\
\hline Low and middle-income countries in Europe & 39 \\
\hline Low and middle-income countries in South-East Asia & 16 \\
\hline Low and middle-income countries in Western Pacific & 25 \\
\hline High-income countries & \\
\hline
\end{tabular}

Note: Data is from the WHO's report Preventing Suicide: A Global Imperative, p.18.

many older people still enjoy job security and generous benefits. The harsh economic in Japan had led to high unemployment, and thus deepen tensions between family members. Family conflict is responsible for the high suicide rate in Japan.

Suicide has a different role in Japan's cultural heritage than it does in the West. In Japan, suicide is considered as a way to take responsibility. The reasons of Japanese suicide are many, according to Japan's National Police Agency statistics, "health problems" the most, followed by "economic and social problems" and "family problems". In fact, the critical factor of committing suicide is economy because economic problem leads to unemployment, increasing conflict and then family problems.

Empirical studies related to suicides are often been conducted with an economic, sociology, epidemiology, or psychology perspective. In this study, we focus on the economic perspective. Economists believe that if future economic growth leads to higher employments and better economic prospects, then people will feel hope and reduce the possibility of suicide. Rodríguez (2005) and Viren (2005) find that economic growth has a significantly negative impact on suicide rates. On the contrary, Gingberg (1966) believes that the economic environment has a positive effect on suicides. One perspective suggests that economic downturns lead to an increase in unemployment and a decrease in the opportunity cost of leisure. Subsequently, due to surrounding friends also suffering unemployment, the unemployed are less likely to experience psychological pressure and as a result, the number of suicide attempts or thus the suicide rates decline (Clark, 2003).

The Asian financial crisis of the late 1990s had serious impacts on South Korea, causing an economic downturn that led to a substantial increase in suicide rates compared to that of the early 1990s. A number of studies (Faupel et al. 1987; Burr et al. 1994; Lester 1995; Mäkinen 1997; Ruhm 2000; Chuang and Huang 2003; Klick and Markowitz 2003; Rodríguez 2005; Daly and Wilson 2006; Koo and Cox 2008; Minoiu and Rodríguez 2008; Chen et al. 2009) argue that high unemployment rates were accompanied by high rates of suicide. However, Clark (2003) and Neumayer (2004) find that unemployment rates are significantly negative related to suicide rates. In this study, we investigate whether high unemployment rate causes high suicide rate in Japan and South Korea, both well developed countries that have high suicide rates. This study provides an economic perspective to discuss the prevention of suicides.

The remaining part of this paper is organized as follows: Section 2 describes the data sets and demonstrates the econometric methodology for the empirical analysis. Section 3 presents the empirical results. Section 4 provides the conclusions.

\section{DATA AND ECONOMETRIC METHODOLOGY}

\subsection{Data}

The data set used in this study consists of annual observations of suicide rate $(S R)$, and unemployment rate (UR) from 1985 to $2012 .^{2}$ Suicide rate data is from the WHO Mortality Database and unemployment rate data is from the International Monetary Fund, World Economic Outlook Database. The summary statistics of suicide rate (per 100,000) and unemployment rate in Japan and South Korea are reported in Table 2.

${ }^{2}$ By the September 2015, suicide rate data from the WHO Mortality Database is available till 2012. Suicide rate data for 2013 was released in September 2015. 
Table 2: Summary Statistics

\begin{tabular}{|c|c|c|c|c|c|c|c|c|}
\hline \multirow{2}{*}{ Variable } & \multicolumn{4}{|c|}{ Japan } & \multicolumn{4}{c|}{ South Korea } \\
\cline { 2 - 10 } & Mean & Max & Min & Std. Dev. & Mean & Max & Min & Std. Dev. \\
\hline \hline$S R$ & 20.47 & 23.90 & 16.70 & 2.41 & 19.26 & 33.80 & 8.40 & 9.13 \\
\hline$U R$ & 3.71 & 5.36 & 2.09 & 1.09 & 3.42 & 6.95 & 2.06 & 1.13 \\
\hline
\end{tabular}

Notes: SR_JPN and SR_KOR represent the suicide rates (per 100,000) in Japan and South Korea, respectively. Meanwhile, UR_JPN and UR_KOR represent the unemployment rates in Japan and South Korea. The sample period is from 1985 to 2012.

\subsection{Asymmetric Granger Causality Test}

Traditionally symmetric granger causality ignores the possibility of asymmetric process and assumes that the impact of a positive shock is the same as that of a negative shock in the absolute terms. However, positive and negative shocks may have different causal impacts. Therefore, this study takes into account this issue and utilizes the asymmetric causality test, as suggested by Hatemi-J (2012), which allows the separation between the causal impact of positive and negative shocks.

This study focuses on the causal relationship between suicide rate $(S R)$ and unemployment rate $(U R)$. Given two integrated variables $S R_{t}$ and $U R_{t}$, they are defined as a random walk process as follows:

$S R_{t}=S R_{t-1}+\varepsilon_{1 t}=S R_{0}+\sum_{i=1}^{T} e_{1 i}$

and

$U R_{t}=U R_{t-1}+\varepsilon_{2 t}=U R_{0}+\sum_{i=1}^{T} e_{2 i}$

where the constants $S R_{0}$ and $U R_{0}$ are the initial values, and variables $e_{1 t}$ and $e_{2 t}$ are white noise error terms. Positive and negative shocks are defined as: $e_{1 t}^{+}=\max \left(e_{1 i}, 0\right), e_{2 t}^{+}=\max \left(e_{2 i}, 0\right), e_{1 t}^{-}=\min \left(e_{1 i}, 0\right)$, and $e_{2 t}^{-}=\min \left(e_{2 i}, 0\right)$, respectively. Thus, we can express $e_{1 t}=e_{1 t}^{+}+e_{1 t}^{-}$and $e_{2 t}=e_{2 t}^{+}+e_{2 t}^{-}$. Equations (1) and (2) can be rewritten as:

$S R_{t}=S R_{t-1}+e_{1 t}=S R_{0}+\sum_{i=1}^{t} e_{1 i}^{+}+\sum_{i=1}^{t} e_{1 i}^{-}$

and

$U R_{t}=U R_{t-1}+e_{2 t}=U R_{0}+\sum_{i=1}^{t} e_{2 i}^{+}+\sum_{i=1}^{t} e_{2 i}^{-}$

The positive and negative shocks of each variable can be defined in a cumulative form as $S R_{t}^{+}=\sum_{i=1}^{t} e_{1 i}^{+}$,
$S R_{t}^{-}=\sum_{i=1}^{t} e_{1 i}^{-}, U R_{t}^{+}=\sum_{i=1}^{t} e_{2 i}^{+}$, and $U R_{t}^{-}=\sum_{i=1}^{t} e_{2 i}^{-}$. Each positive and negative shock has a permanent impact on the underlying variable. To test the causal relationship between these two components, Hatemi-J (2012) and Hatemi-J and Uddin (2012) developed a single test statistic in time domain, assuming it holds for all points in the frequency distribution. There are four combinations of positive and negative shocks $\left(\left(S R_{t}^{+}, U R_{t}^{+}\right), \quad\left(S R_{t}^{+}, U R_{t}^{-}\right),\left(S R_{t}^{-}, U R_{t}^{+}\right), \quad\left(S R_{t}^{-}, U R_{t}^{-}\right)\right)$as suggested by Hatemi-J and Uddin (2012). The test for asymmetric causality can be conducted by using a vector autoregressive (VAR) model with optimal lag length $(p)$ as follows:

$X_{t}^{c}=\gamma+A_{1} X_{t-1}^{c}+A_{2} X_{t-2}^{c}+A_{3} X_{t-3}^{c}+\cdots+A_{p} X_{t-p}^{c}+u_{t}^{c}$

where $X_{t}^{c}=\left(S R_{t}^{c}, U R_{t}^{c}\right), \gamma$ is the $2 \times 1$ intercept vector, $A_{i}$ is the $2 \times 2$ matrix of parameters, $c$ is the type of components (i.e. positive "+" or negative "-"), and $u$ is the $2 \times 1$ vector of error terms. The optimal lag length $p$ is selected by the following information criterion that is suggested by Hatemi-J (2003):

$$
H J C=\ln \left(\left|\hat{\Omega}_{j}\right|\right)+j\left(\frac{n^{2} \ln T+2 n^{2} \ln (\ln T)}{2 T}\right), \quad j=0,1, \cdots, p
$$

where $\left|\hat{\Omega}_{j}\right|$ is the determinant of the estimated variance-covariance matrix of the error terms in the VAR model based on the lag length $j, n$ is the number of equations in the VAR, and $T$ is the total number of observations.

Then, we use a Wald test to test for Granger causality via the $\operatorname{VAR}(p)$ model defined as follows:

$X=D Z+\delta$

where

$X=\left(X_{1}^{c}, \cdots, X_{T}^{c}\right) \quad(n \times T)$ matrix;

$D=\left(\gamma, A_{1}, \cdots, A_{p}\right) \quad(n \times(1+n p))$ matrix;

$Z_{t}=\left[\begin{array}{c}1 \\ X_{t}^{c} \\ X_{t-1}^{c} \\ \vdots \\ X_{t-p+1}^{c}\end{array}\right]((1+n p) \times 1)$ matrix for $t=1, \cdots, T$; 
$Z=\left(Z_{0}, \cdots, Z_{T-1}\right)((1+n p) \times T)$ matrix;

$\delta=\left(u_{1}^{c}, \cdots, u_{T}^{c}\right) \quad(n \times T)$ matrix.

The null hypothesis of no Granger causality, $H_{0}: R \beta=0$, is tested by the following:

Wald $=(R \beta)^{\prime}\left[R\left(\left(Z^{\prime} Z\right)^{-1} \otimes S\right) R^{\prime}\right]^{-1}(R \beta)$

where $R$ is an indicator matrix of the parameters with elements ones for restricted parameters and zero for the rest of the parameters, $\beta$ is the column stack of $D$, $\otimes$ represents the Kronecker product, and $S$ is the variance-covariance matrix of the unrestricted model. As noted by Hatemi-J and Uddin (2012), If the data exists the autoregressive conditional heteroskedasticity $(\mathrm{ARCH})$ effects, then there is the possibility that the distribution of the Wald statistic substantially deviates from its asymptotic distribution. Therefore, it is important to utilize the bootstrapping simulation technique in order to achieve correct inference.

\section{EMPIRICAL RESULTS}

The Phillips-Perron unit root test was adopted to determine the integration degree of variables before conducting the asymmetric Granger causality test. The results of Phillips-Perron unit root test are reported in Table 3. As shown in Table 3, we cannot reject the null hypothesis of a unit root for all variables in levels but we can reject the null hypothesis of a unit root for all variables in first differences. Hence, all variables are integrated of one order.

This study also adopts Toda and Yamamto (1995)'s $\operatorname{VAR}(p+d)$ model, where $p$ is the optimal lag and $d$ is the maximum order of integration. The maximum order of integration $\mathrm{d}$ is equal to 1 for both Japan and South Korea. Meanwhile, for Japan and South Korea, the optimal lag length $p$ in the VAR model is equal to 1 determined by the HJC information criterion.

Diagnostic test results are reported in Table 4. We adopt the Doornik and Hansen (2008) test for multivariate normality and Hacker and Hatemi-J (2005) test for $\mathrm{ARCH}$. For both Japan and South Korea, the null hypothesis that residuals are multivariate normal is rejected regardless whether the VAR model is estimated for positive, negative, or a combination of the cumulative shocks. The null hypothesis of no multivariate $\mathrm{ARCH}$ is also rejected for all four cases in Japan and South Korea. Therefore, this study utilizes the bootstrap test instead of the standard methods based on normality and no $\mathrm{ARCH}$. The bootstrapping simulation technique based on Hatemi-J and Uddin (2012) for 10,000 iterations is utilized to construct the $10 \%, 5 \%$, and $1 \%$ critical values by using GAUSS software.

The test results of Asymmetric Granger causality running from unemployment rate to suicide rate in Japan and South Korea are reported in Tables $\mathbf{5}$ and $\mathbf{6}$,

Table 3: Phillips-Perron Test for Unit Root

\begin{tabular}{|c|c|c|c|c|}
\hline \multirow{2}{*}{ Variable } & \multicolumn{2}{|c|}{ Japan } & \multicolumn{2}{c|}{ South Korea } \\
\cline { 2 - 5 } & Test Statistic (Level) & Test Statistic (1st Difference) & Test Statistic (Level) & Test Statistic (1st Difference) \\
\hline \hline$S R^{+}$ & $-0.65310[0.8416]$ & $-4.67109^{\star * *}[0.0011]$ & $0.277442[0.9723]$ & $-4.60469^{\star * *}[0.0013]$ \\
\hline$S R$ & $0.63573[0.9880]$ & $-3.00412^{\star *}[0.0482]$ & $-0.90711[0.7696]$ & $-4.01606^{\star * \star}[0.0051]$ \\
\hline$U R^{+}$ & $-0.17733[0.9299]$ & $-4.14637^{\star * *}[0.0037]$ & $-0.86075[0.7843]$ & $-4.55298^{\star * \star}[0.0014]$ \\
\hline$U R$ & $-1.97557[0.2950]$ & $-3.73261^{* * *}[0.0098]$ & $0.91061[0.9940]$ & $-3.78554^{* * *}[0.0087]$ \\
\hline
\end{tabular}

Notes: The $p$-value is presented in the bracket. ${ }^{* *}$ and ${ }^{* *}$ indicate significance at the $1 \%$ and $5 \%$ levels, respectively

Table 4: Diagnostic Test Results

\begin{tabular}{|c|c|c|c|c|}
\hline \multirow{2}{*}{$\begin{array}{c}\text { Variable in the VAR } \\
\text { model }\end{array}$} & \multicolumn{2}{|c|}{ Japan } & \multicolumn{2}{c|}{ South Korea } \\
\cline { 2 - 5 } & Multivariate Normality & Multivariate ARCH & Multivariate Normality & Multivariate ARCH \\
\hline \hline$\left(S R^{+}, U R^{+}\right)$ & 0.0000 & 0.3860 & 0.0000 & 0.0940 \\
\hline$\left(S R^{-}, U R\right)$ & 0.0008 & 0.8860 & 0.0000 & 0.5110 \\
\hline$\left(S R, U R^{+}\right)$ & 0.0001 & 0.2210 & 0.0001 & 0.1170 \\
\hline$\left(S R^{+}, U R^{-}\right)$ & 0.0001 & 0.1270 & 0.0001 & 0.1480 \\
\hline
\end{tabular}

Notes: The p-values for multivariate normality and multivariate ARCH tests are presented. The optimal lag length in the VAR model is one based on the HJC information criterion. 
Table 5: Asymmetric Granger Causality Tests Running from Unemployment Rate to Suicide Rate in Japan

\begin{tabular}{|c|c|c|c|c|}
\hline \multirow{2}{*}{ Null Hypothesis } & \multirow{2}{*}{ Test Statistics } & \multicolumn{3}{|c|}{ Bootstrap } \\
\cline { 3 - 5 } & & CV at 1\% & CV at 5\% & CV at 10\% \\
\hline \hline$U R^{+} \neq>S R^{+}$ & 1.429 & 16.546 & 5.290 & 3.222 \\
\hline$U R \neq>S R^{-}$ & 2.474 & 10.453 & 4.492 & 3.094 \\
\hline$U R^{-} \neq>S R^{+}$ & 0.008 & 9.540 & 4.409 & 2.600 \\
\hline$U R^{+} \neq>S R^{-}$ & 0.443 & 8.938 & 4.149 & 2.836 \\
\hline
\end{tabular}

Notes: The denotation $U R^{+} \neq>S R^{+}$means that positive unemployment rate shocks do not Granger cause positive shocks in suicide rate and $U R \neq>S R^{-}$means that negative unemployment rate shocks do not Granger cause negative shocks in suicide rate.

Table 6: Granger Causality Running from Unemployment Rate to Suicide Rate in South Korea

\begin{tabular}{|c|c|c|c|c|}
\hline \multirow{2}{*}{ Null Hypothesis } & \multirow{2}{*}{ Test Statistics } & \multicolumn{3}{|c|}{ Bootstrap } \\
\cline { 3 - 5 } & & CV at 1\% & CV at 5\% & CV at 10\% \\
\hline \hline$U R^{+} \neq>S R^{+}$ & 0.020 & 14.206 & 5.499 & 3.148 \\
\hline$U R^{-} \neq>S R^{+}$ & $10.111^{* *}$ & 13.478 & 4.804 & 2.964 \\
\hline$U R^{-} \neq>S R^{+}$ & 0.098 & 11.958 & 5.329 & 3.319 \\
\hline$U R^{+} \neq>S R^{-}$ & 1.889 & 9.461 & 4.681 & 3.067 \\
\hline
\end{tabular}

Notes: The denotation $U R^{+} \neq>S R^{+}$means that positive unemployment rate shocks do not Granger cause positive shocks in suicide rate and $U R \neq>S R^{-}$means that negative unemployment rate shocks do not Granger cause negative shocks in suicide rate . ${ }^{* *}$ indicates significance at the $5 \%$ level.

respectively. As shown in Table 5, there is no Granger causality running from unemployment rate to suicide rate in terms of positive, negative, or a combination of the cumulative shocks in Japan. For South Korea, according to the asymmetric causality test results in Table 6, only the null hypothesis that negative unemployment rate shocks do not Granger cause negative shocks in suicide rate (i.e. $U R^{-} \nRightarrow S R$ ) can be rejected at the $5 \%$ significance level. This result indicates that a negative shock from unemployment rate will further decrease suicide rate.

\section{CONCLUSIONS}

The traditional symmetric Granger causality test assumes that the impact of a positive shock is the same as that of a negative shock in the absolute terms. However, positive and negative shocks may have different causal impacts. This study takes into account this issue and utilizes an asymmetric Granger causality test suggested by Hatemi-J (2012) in order to examine the causal relationship running from unemployment rate to suicide rate over the period of 1985 to 2012 in Japan and South Korea.

Empirical results show that there is no Granger causality running from unemployment rate to suicide rate in Japan but there is Granger causality running from unemployment rate to suicide rate in South Korea. For South Korea, test results from an asymmetric causality test suggest that a negative unemployment rate shock will cause a negative shock in suicide rate. More specifically, a decrease in unemployment rate leads to a decrease in suicide rate.

The findings of this study indicate that policy makers in South Korea could decrease unemployment rate to cause a decrease in suicide rate. However, there is no significant evidence to support that a positive unemployment rate shock will cause a positive shock in suicide rate in South Korea. Therefore, for both Japan and South Korea, we have no sufficient evidence to support that an increase in unemployment rate causes an increase in suicide rate.

\section{REFERENCES}

Burr, J. A., P. L. McCall, and E. Powell-Griner. 1994. "Catholic Religion and Suicide: The Mediating Effect of Divorce." Social Science Quarterly 75(2): 300-318.

Chen, J., Y. J. Choi, and Y. Sawada. 2009. "How is Suicide Different in Japan?" Japan and the World Economy 21(2): 140-150. http://dx.doi.org/10.1016/j.japwor.2008.06.001

Chuang, H. and W. Huang. 2003. "Suicide and Unemployment: Is There a Connection? An Empirical Analysis of Suicide Rates in Taiwan." Journal of Socio-Economics 26(3): 277-289.

Clark, A. E. 2003. "Unemployment as a Social Norm: Psychological Evidence from Panel Data." Journal of Labor Economics 21: 323-351. http://dx.doi.org/10.1086/345560

Daly, M. C. and D. J. Wilson. 2006. "Keeping Up with the Joneses and Staying Ahead of the Smiths: Evidence from Suicide Data." Federal Reserve Bank of San Francisco Working Paper 2006-12. 
Faupel, C. E., G. S. Kowalski, and P. D. Starr. 1987. "Sociology's One Law: Religion and Suicide in the Urban Context." Journal for the Scientific Study of Religion 26: 523-534. http://dx.doi.org/10.2307/1387102

Ginsberg, R. B.. 1980. Anomic and Aspiration: A Reinterpretation of Durkhiem's Theory. New York: Arno Press.

Hatemi-J, A. 2003. "A New Method to Choose Optimal Lag Order in Stable and Unstable VAR Models." Applied Economic Letters 10 (3): 135-137. http://dx.doi.org/10.1080/1350485022000041050

Hatemi-J, A. 2012. "Asymmetric Causality Tests with an Application." Empirical Econonomics 43 (1): 447-456. http://dx.doi.org/10.1007/s00181-011-0484-x

Hatemi-J, A. and G. S. Uddin. 2012. "Is the Casual Nexus of Energy Utilization and Economic Growth Asymmetric in the US?" Economic Systems 36: 461-469. http://dx.doi.org/10.1016/i.ecosys.2011.10.005

Klick, J. and S. Markowitz. 2003. "Are Mental Health Insurance Mandates Effective? Evidence from Suicides." Health Economics 15(1): 83-97. http://dx.doi.org/10.1002/hec. 1023

Koo, J. and M. Cox. 2008. "An Economic Interpretation of Suicide Cycles in Japan." Contemporary Economic Policy 26: 162174. http://dx.doi.org/10.1111/j.1465-7287.2007.00042.x

Lester, D. 1995. "Explaining Regional Differences in Suicide Rates." Social Sciences and Medicine 40(5): 719-721. http://dx.doi.org/10.1016/0277-9536(95)80015-C
Mäkinen, I. 1997. "Are There Social Correlates to Suicide?" Social Science and Medicine 44: 1919-1929. http://dx.doi.org/10.1016/S0277-9536(97)00016-6

Minoiu, C. and A. Rodríguez. 2008. "The Effect of Public Spending on Suicide: Evidence from U.S. State Data." The Journal of Socio-Economics 37: 237-261. http://dx.doi.org/10.1016/j.socec.2006.09.001

Neumayer, E. 2004. "Recessions Lower (Some) Mortality Rates: Evidence from Germany." Social Science and Medicine 58: 1037-1047. http://dx.doi.org/10.1016/S0277-9536(03)00276-4

Rodríguez, A. A. 2005. "Income Inequality, Unemployment, and Suicide: A Panel Data Analysis of 15 European Countries." Applied Economics 37(4): 439-451. http://dx.doi.org/10.1080/0003684042000295304

Ruhm, C. J. 2000. "Are recessions good for your health?" Quarterly Journal of Economics 115: 617-650. http://dx.doi.org/10.1162/003355300554872

Värnik, P. 2012. "Suicide in the World." International Journal of Environmental Research and Public Health 9(3): 760-771. http://dx.doi.org/10.3390/ijerph9030760

Viren, M. 2005. "Suicide and Business Cycles: New Empirical Evidence." Applied Economics Letters 12(14): 887-891. http://dx.doi.org/10.1080/13504850500359411

Received on 02-03-2016

Accepted on 17-05-2016

Published on 30-05-2016

DOI: http://dx.doi.org/10.6000/1929-7092.2016.05.14

(C) 2016 Huang and Ho; Licensee Lifescience Global.

This is an open access article licensed under the terms of the Creative Commons Attribution Non-Commercial License (http://creativecommons.org/licenses/by-nc/3.0/) which permits unrestricted, non-commercial use, distribution and reproduction in any medium, provided the work is properly cited. 